\title{
Reply to Professor Hermanek's comments on the new Japanese classification of gastric carcinoma
}

\author{
Mitsuru SASAKo ${ }^{1}$ and TAKashi Aiko ${ }^{2}$ \\ ${ }^{1}$ Gastric Surgery Division, National Cancer Center Hospital, 5-1-1 Tokyo Tsukiji, Japan \\ ${ }^{2}$ First Department of Surgery, Kagoshima University School of Medicine, Kagoshima, Japan
}

To the Editor: We thank Dr. Hermanek for his valuable comments Letter to the editor, this issue after thorough review of the new Japanese classification. We would like to reply to several points raised by him.

He seemed somehow disappointed that there are still many important differences between this classification and the International Union Against Cancer (UICC) TNM classification. This is due to major differences in the principles or philosophies of classifying a tumor and evaluating the treatment given. The philosophy of the Japanese classification is explained in detail in the article by Aiko and Sasako [1] in the same issue of Gastric Cancer. It is a pity that Professor Hermanek did not seem to refer to this explanatory article, which clarified the benefit of the new Japanese classification over the TNM classification. The most important point is that the Japanese classification aims to have wide applicability of prospective decision-making in treatment, including surgical and nonsurgical treatment, such as neoadjuvant chemotherapy. Many histological findings, such as the results of laparoscopic or intraoperative biopsy, are now being used for reaching treatment decisions. In this manner, the simple categorization of clinical or pathological stages employed by the UICC system has become impractical, because the clinical classification cannot include any histopathological findings and they are mutually exclusive categories [2].

Although there are major differences between the two classifications, we are continuous making efforts to adopt acceptable rules of TNM classification. In the new version, many points were adopted from the TNM classification; for example, the method of description (such as $\mathrm{pT}$ and $\mathrm{pN}$ instead of the use of capital letters for macroscopic findings, and the use of small letters for histological findings, as was done in the previous version), and the subclassification of pT factors.

One of the most remarkable differences between the two systems is in the $\mathrm{N}$ classification. The new $\mathrm{pN}$ classification of the UICC system is very theoretical, based on the prognostic analysis according to the number of metastatic nodes, and it is not as practical when surgery is planned. $\mathrm{N}$ classification during surgery is impossible because surgeons cannot count the number of metastatic lymph nodes during surgery. It has already been reported that macroscopic judgment of the metastatic state of lymph nodes is often wrong [3-7]. The UICC system describes both an $\mathrm{N}$ classification and a $\mathrm{pN}$ classification, but the former will never be used by surgeons and is actually excluded from the new TNM classification.

Which correlates better with prognosis, the number of metastatic lymph nodes or the topographic location of metastatic nodes, is still controversial. However, there is a strong correlation between the number of metastatic nodes and the topographic stage. With an extensive revision of the classification of several lymph node stations, the new Japanese classification corresponds better with prognosis than the former version, especially with the change of the five-category system (N0 to N4) to four categories (N0 to N3). Its suitability for planning surgery and high prognostic relevance are the reasons that the Japanese classification has been widely accepted in many countries outside Japan.

The advantage of the topographic classification is that one positive node sampled from the second or third tier can provide the correct $\mathrm{pN}$ stage and that stage migration occurs less than it does in a number system when the proportion of examined nodes is much smaller than the real number of regional lymph nodes. The topographic system is much more feasible than the number system in many countries where fewer than 15 nodes are usually examined for one specimen.

Professor Hermanek pointed out that, because the new version of the Japanese classification adopted subdivisions of splenic artery nodes and nodes in the hepatoduodenal ligament, patients classified by $\mathrm{N}$ and $\mathrm{M}$ category according to the 1st English edition could 
not be compared with those classified according to the new rules. Very few patients are actually affected by this subdivision of hepatoduodenal nodes. Regarding splenic artery nodes, if they are positive in those undergoing distal gastrectomy, they should be regarded as $11 \mathrm{p}$ (proximal), and in those undergoing total gastrectomy, $11 \mathrm{p}$ and $11 \mathrm{~d}$ usually belong to the same tiers. By this interpretation, the old classification is completely comparable with the new classification.

Regarding the criticism of histopathological classification, more effort should be made to unify histopathological classification internationally among pathologists. The UICC adopts the principle of applicability in all organs. The Japanese classification does not fit organs other than the stomach. However, if gastric cancer is considered exclusively, the Japanese histopathological classification is more practical than that of the UICC. Pathologists' efforts, shown by the Vienna proposal regarding biopsy classification, should be extended to the final diagnosis of gastric carcinoma.

Professor Hermaneck's criticism of the classification of lymph node dissection is not appropriate, as there is no definition of the D classification in the UICC system. In the majority of publications on gastric cancer surgery in the past 3 years, the Japanese D system has been used to describe the degree or extent of nodal dissection. In the UICC system, regional lymph nodes are defined clearly irrespective of the tumor location. It is not clearly stated, however, that all regional lymph nodes should be dissected. Theoretically, they should all be dissected to achieve accurate staging, wherever the tumor is located. But from the point of view of clinical benefit, it is a wrong idea to take out all regional lymph nodes. Especially, with the markedly higher mortality seen with total gastrectomy than with distal gastrectomy in the two recent clinical trials $[8,9]$, unnecessary total gastrectomy should be avoided. The new version of the Japanese classification is, for the first time, based on the incidence of metastasis and 5-year survival rate of those with metastasis in each station, according to the tumor location. Therefore the staging is based clearly on the clinical benefit of dissection and prognosis. After the elimination of the categoly of optional stations, which were the major source of misunderstanding of the area to dissect, dissecting all second-tier stations leads to a reasonable resection and unnecessary total gastrectomy can automatically be avoided.

Professor Hermanek mentioned that circumferential resection margins should be assessed to give an $\mathrm{R}$ classification or classification of curative potential. Of course this is done in the Japanese classification, but more practically. Theoretically, pathological assessment of a T4 tumor can be done in all patients. If autopsy material actually resected en bloc with all tissues anterior to the vertebra is examined, true evaluation of circumferential margins is possible. However, how can pathologists be exact when they see a gastrectomy specimen? The stomach is not embedded in connective tissue. If a gastric cancer invades to the mesocolon or nerve tissue surrounding the major branches of the celiac artery, how can the pathologist judge resection margins exactly without making 5-mm continuous sections of en-bloc resected material? Who would do this? Surgeons can recognize well the part where the dissection or division was difficult and can point this out to pathologists as a potential area of residual tumor. Thus, very effectively, circumferential margins are examined in Japan. Of course if some potentially invaded organs such as the pancreas are resected together with the tumor, margins can easily be assessed by pathologists at any institute. We believe Professor Hermanek's worry on this matter was not relevant. In answer to his comments on the new description of the curative potential in terms of the distal or proximal margin, we would like to add some explanation. In this version, the judgment of curative potential in regard to surgical margins is made on whether margins are larger than $10 \mathrm{~mm}$ or not on both macroscopic and pathological staging. So Table 6 (page 30) in the article by Aiko and Sasako [1], explaining the principles of the assessment of curative potential, should be corrected; "margin $>5 \mathrm{~mm}$ " should be replaced by "margin $>10 \mathrm{~mm}$ ".

The new Japanese classification of gastric carcinoma itself, the special article explaining the new classification, Professor Hermanek's letter to the Editor, and this answer to his comments, all together have successfully clarified the different philosophies of the two classifications. In the near future, by the efforts of both sides (Japan and the UICC), and probably by the efforts of clinicians and pathologists, these two classifications will become more harmonized, to be a single international system.

\section{References}

1. Aiko T, Sasako M, for the General rules' Committee of the Japanese Gastric Cancer Association. The new Japanese classification of gastric carcinoma: points to be revised. Gastric Cancer 1999;1:25-30.

2. International Union Against Cancer. Sobin LH, Wittekind Ch. TNM Classification of malignant tumours. 5th ed. Heidelberg Berlin New York Tokyo: Springer-Verlag; 1997.

3. Madden MV, Price SK, Learmonth GM, Dent DM. Surgical staging of gastric carcinoma: sources and consequences of error. Br J Surg 1987;74:119-21.

4. Gunven P, Maruyama K, Okabayashi K, Sasako M, Kinoshita T. Non-ominous micrometastases of gastric cancer. $\mathrm{Br} \mathrm{J}$ Surg 1991;78:352-4.

5. Ziegler K, Sanft C, Zeitz M, Felsenberg D, Stein H, Germer C, et al. Comparison of computed tomography, endosonography, and intraoperative assessment in TN staging of gastric carcinoma. Gut 1993;34:604-10. 
6. Natsugoe S, Aiko T, Yotsumoto K, Yoshinaka H, Shimazu H. Comparative study on macroscopic and histopathological diagnosis for lymph node metastases in cancer patients (in Japanese with English abstract). Jpn J Surg 1987;88:258-65.

7. Noda N, Sasako M, Yamaguchi N, Nakanishi Y. Ignoring small lymph nodes can be a major cause of staging error in gastric cancer. Br J Surg 1998;85:831-4.

8. Bonenkamp JJ, Songun I, Hermans J, Sasako M, Welvaart K,
Plukker JTM, et al. Randomised comparison of morbidity after D1 and D2 dissection for gastric cancer in 996 Dutch patients. Lancet 1995;345:745-8.

9. Cuschieri A, Fayers P, Fielding J, Craven J, Bancewicz J, Joypaul V, et al. Postoperative morbidity and mortality after D1 and D2 resections for gastric cancer: preliminary results of the MRC randomized controlled surgical trial. Lancet 1996;347: 995-9. 